02

\title{
Электрон-фононное взаимодействие в композитах с колллоидными квантовыми точками: исследование методами люминесцентной спектроскопии и комбинационного рассеяния света
}

\author{
(C) К.Р. Каримуллин ${ }^{1,2,3}$, А.И. Аржанов ${ }^{1,2}$, Н.В. Суровцев ${ }^{4}$, А.В. Наумов ${ }^{1,2,3}$ \\ ${ }^{1}$ Институт спектроскопии РАН, \\ 108840 Москва, Троицк, Россия \\ ${ }^{2}$ Московский педагогический государственный университет, \\ 119435 Москва, Россия \\ ${ }^{3}$ Физический институт им. П.Н. Лебедева РАН, \\ Троицкое обособленное подразделение, включающее „Троицкий Технопарк ФИАН“, \\ 108840 Москва, Троицк, Россия \\ ${ }^{4}$ Институт автоматики и электрометрии Сибирского отделения РАН, \\ 630090 Новосибирск, Россия \\ e-mail: kamil@isan.troitsk.ru
}

Поступила в редакцию 20.08.2021 г.

В окончательной редакции 06.09.2021 г.

Принята к публикации 14.09.2021 г.

По спектрам люминесценции, зависящим от температуры, определены параметры электрон-фононного взаимодействия (фактор Хуанга-Риса, средняя энергия фононов) для нанокомпозитов с коллоидными квантовыми точками $\mathrm{CdSe} / \mathrm{CdS} / \mathrm{ZnS}$ (на поверхности стеклянной подложки, в тонкой полимерной пленке полиизобутилена и в замороженном коллоидном растворе в толуоле). Измеренные значения проанализированы в сравнении с модельными расчетами и данными, полученными с использованием техники низкочастотного комбинационного рассеяния света. Обнаружено, что в случае застеклованного коллоидного раствора квантовых точек в толуоле эффект матрицы приводит к заметному изменению параметров электрон-фононного взаимодействия.

Ключевые слова: квантовая точка, нанокомпозит, полимер, фонон, электрон-фононное взаимодействие.

DOI: $10.21883 /$ OS.2022.01.51902.42-21

\section{Введение}

Современная фотоника и ее разнообразные междисциплинарные приложения требуют решения широкого круга задач, среди которых особое место занимают инжиниринг новых наноструктурированных материалов с заданными (управляемыми) свойствами и развитие методов исследования таких систем [1]. Одним из уникальных новых материалов, которые становятся основой все большего количества новых технологий, являются полупроводниковые нанокристаллы (квантовые точки, КТ). Актуальной фундаментальной задачей в этой области стало исследование фотофизических свойств и внутренней динамики нанокомпозитов на основе КТ [2]. Значительные усилия в настоящее время направлены на поиск и изучение новых люминофоров [3] и подходящих твердотельных матриц для синтеза функциональных материалов на основе КТ, например полимеров [4], жидких кристаллов [5], гибридных структур [6].

Квантовые точки имеют ряд специфических фотофизических и спектральных свойств, которые определяются их структурой, размерами и микроскопическими особенностями взаимодействия со средой. Совокупность этих свойств обусловливает широкую область приме- нения КТ в физике, материаловедении, биологии и медицине [7]. Разработка новых материалов на основе КТ требует изучения на фундаментальном уровне динамических процессов в КТ, тогда как поиск новых люминесцентных меток связан с прояснением вопроса о взаимодействии КТ с твердыми матрицами, в частности, электрон-фононном взаимодействии [8-11]. Одним из наиболее эффективных методов исследования динамических свойств примесных твердотельных материалов является спектроскопия фотонного эха [12-14], однако классическая люминесцентная спектроскопия, дополненная температурными измерениями, также может быть эффективной в исследованиях такого типа [15]. Потенциал данной техники существенно расширяется при совместном использовании других экспериментальных техник, в частности, низкочастотного комбинационного рассеяния света (КРС), где колебательные характеристики (энергия фононов) могут быть измерены напрямую [16].

\section{Образцы и методы исследования}

Ранее нами были исследованы образцы, представляющие собой тонкие слои двухоболочечных коллоидных 
KT CdSe/CdS/ZnS, высаженных на стеклянную подложку $[14,17,18]$. В настоящей работе исследованы те же самые КТ, внедренные в твердые матрицы: замороженный толуол и полиизобутилен (ПИБ). Для изготовления композитов использовали высококонцентрированный раствор КТ $\mathrm{CdSe} / \mathrm{CdS} / \mathrm{ZnS}$ в толуоле $(96 \mathrm{mg} / \mathrm{ml}$, производство QD-Light, Россия). Тонкая пленка ПИБ была изготовлена методом центрифугирования на стеклянной подложке из смеси полимера с раствором КТ с последующим удалением растворителя в вакуумной печи.

Для того чтобы разделить вклады в оптическую дефазировку процессов взаимодействия КТ с матрицей и процессов внутри самих КТ, были измерены зависимости спектров люминесценции нанокомпозитов от температуры. В качестве источника излучения для возбуждения люминесценции образцов использовали полупроводниковый лазерный модуль с длиной волны $515 \mathrm{~nm}$ и выходной мощностью $200 \mathrm{~mW}$. Излучение ослабляли нейтральными фильтрами и фокусировали на образце с помощью объектива. Для измерения спектров люминесценции в диапазоне температур от 24 до $300 \mathrm{~K}$ использовали гелиевый криостат RTI (Черноголовка). При помощи температурного контроллера Lakeshore DRC-91C и системы маностатирования измерительной камеры криостата были выполнены прецизионные температурные измерения с минимальным шагом $0.2 \mathrm{~K}$. Спектры люминесценции образцов регистрировали с помощью компактного волоконного спектрометра (OtO Photonics, Китай).

\section{Анализ спектров люминесценции нанокомпозитов с КT, зависящих от температуры}

Для всех образцов были измерены спектры люминесценции в широком диапазоне температур. Спектры представляют собой симметричные полосы, соответствующие экситонной люминесценции, с шириной порядка $20-30 \mathrm{~nm}$. В зависимости от матрицы-основы композита спектры отличались положением максимума пика экситонной люминесценции (энергии экситона). При понижении температуры максимумы экситонных полос в спектрах люминесценции смещались в УФ область спектра. На рис. 1 показаны зависимости энергии экситона от температуры для трех образцов КT $\mathrm{CdSe} / \mathrm{CdS} / \mathrm{ZnS}$ : высаженных на поверхность стеклянной подложки (кривая 1), внедренных в полиизобутилен (кривая 2) и в замороженный толуол (кривая 3).

Как показал анализ литературы, впервые зависимость ширины запрещенной зоны от температуры для объемных полупроводников была эмпирически описана Варш-

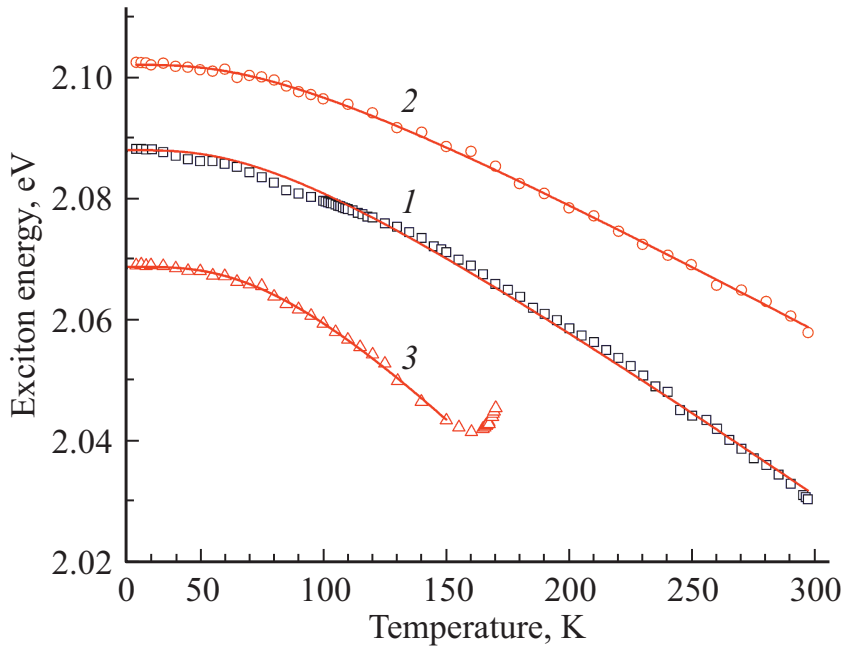

Рис. 1. Температурные зависимости положения максимума спектра люминесценции (энергии экситона) для нанокомпозитов на основе КТ CdSe/CdS/ZnS, высаженных на поверхность стеклянной подложки (1), внедренных в ПИБ (2), внедренных в замороженный толуол (3), и их аппроксимация (сплошные линии) с использованием формулы (2).

ни [19] в виде

$$
E_{g}(T)=E_{g}(0)-\frac{\alpha T^{2}}{\beta+T},
$$

где $E_{g}(0)$ - ширина запрещенной зоны при $0 \mathrm{~K}, \alpha$ и $\beta-$ параметры.

Однако это соотношение малоинформативно для исследования параметров электрон-фононного взаимодействия КТ с матрицей [20]. В работе О’Доннела и Чена [21] была выведена аналитическая формула для описания зависимости от температуры:

$$
E_{g}(T)=E_{g}(0)-\frac{2 S E_{L O}}{\exp \left(\frac{E_{L O}}{k T}\right)-1},
$$

которая содержит дополнительные параметры, характеризующие силу электрон-фононного взаимодействия - $S$ (фактор Хуанга-Риса) и среднюю энергию фононов при релаксации электронного возбуждения $E_{L O}$.

Путем аппроксимации полученных в эксперименте температурных зависимостей энергии экситона формулой (2) были получены значения параметров электронфононного взаимодействия для разных образцов с КТ (таблица).

Полученные значения ширины запрещенной зоны $E_{g}(0)$ практически одинаковы для всех образцов и соответствуют ширине запрещенной зоны для объемного полупроводника и наночастиц CdSe [22]. Исследования показывают, что величина $E_{g}(0)$ может довольно сильно варьироваться в зависимости от концентрации КТ в конкретном образце [23], и это обстоятельство также 
Параметры электрон-фононного взаимодействия для нанокомпозитов с КТ CdSe/CdS/ZnS, вычисленные на основе анализа спектров люминесценции, зависящих от температуры, и спектров КРС

\begin{tabular}{|c|c|c|c|c|}
\hline Образец & $E_{g}(0), \mathrm{eV}$ & $S$ & $E_{L O}, \mathrm{~cm}^{-1}$ & $\begin{array}{c}\text { Частота линии } \\
\text { в спектре КРС, } \mathrm{cm}^{-1}\end{array}$ \\
\hline $\begin{array}{l}\text { КТ/ПИБ } \\
\text { КТ на стекле } \\
\text { КТ/толуол }\end{array}$ & $\begin{array}{l}2.10 \pm 0.02 \\
2.09 \pm 0.02 \\
2.07 \pm 0.02\end{array}$ & $\begin{array}{l}1.31 \pm 0.02 \\
1.67 \pm 0.02 \\
2.66 \pm 0.10\end{array}$ & $\begin{array}{l}170 \pm 3 \\
172 \pm 4 \\
183 \pm 5\end{array}$ & $\begin{array}{c}206.1 \pm 0.2 \\
205.5 \pm 0.2 \\
-\end{array}$ \\
\hline
\end{tabular}

необходимо учитывать, поскольку КТ по-разному распределяются внутри разных матриц. Ширина запрещенной зоны связана не только с энергетическим зазором между уровнями валентной зоны и зоны проводимости для объемного полупроводника, но и с размерами самих нанокристаллов. Для определения характерных размеров и состава используемых нами КТ были проведены дополнительные измерения с использованием просвечивающего электронного микроскопа (ПЭМ, ЦКП „Исследования наноструктурных, углеродных и сверхтвердых материалов“ ФГБНУ ТИСНУМ, Москва). На основе обработки изображений, полученных с ПЭМ, была построена статистика распределения нанокристаллов по размерам $d$. С использованием экспериментальных данных для зависимости энергии экситона от размеров КТ $\mathrm{CdSe}$ [24] был определен диапазон возможных значений $E_{g}(0): 2.04-2.16 \mathrm{eV}$, что хорошо соответствует значениям $E_{g}(0)$, полученным в результате аппроксимации зависимостей спектров люминесценции композитов с КТ $\mathrm{CdSe} / \mathrm{CdS} / \mathrm{ZnS}$ от температуры.

Полученные значения фактора Хуанга-Риса $S$ довольно сильно отличаются для разных образцов, т. е. наличие окружающей матрицы сильно влияет на параметры электрон-фононного взаимодействия. Наибольшее значение $S$ получено для КТ, внедренных в толуол. Это может быть связано с влиянием термического расширения твердого толуола на электронно-колебательный спектр [20]. Кроме того, большое значение фактора Хуанга-Риса может быть связано с высокой концентрацией КТ.

Значения $E_{L O}$ для разных образцов также отличаются, что может свидетельствовать о заметном эффекте гибридизации колебательных (фононных) мод - о взаимодействии излучающего ядра КТ не только с локальными фононами КТ, но и с фононами матрицы. Твердотельные матрицы, используемые для приготовления образцов, характеризуются собственным фононным спектром, что приводит к различиям в значениях средней энергии фононов $E_{L O}$, локализованных внутри КТ. Различия в параметрах электрон-фононного взаимодействия приводят к заметному изменению эффективной частоты локального фонона, что свидетельствует о сильном влиянии динамики матрицы на спектральные и люминесцентные свойства КТ. Последний вывод подтверждается поведением температурной зависимости замороженного толуола вблизи температуры стеклования (165 K). Характер

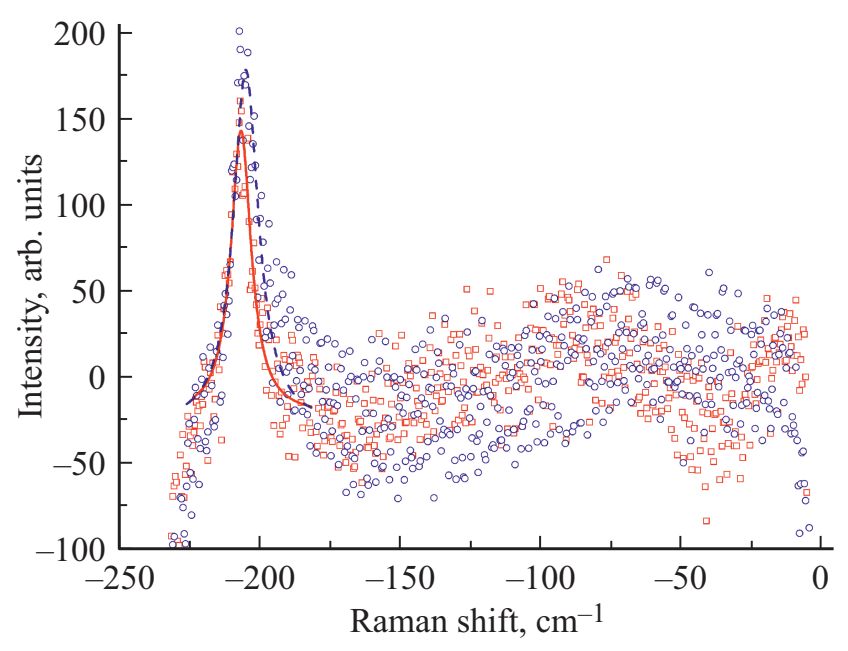

Рис. 2. Спектры КРС (антистоксова компонента; после вычитания фона) для КТ $\mathrm{CdSe} / \mathrm{CdS} / \mathrm{ZnS}$ на стеклянной подложке (красные квадраты) и КТ, внедренных в ПИБ (синие кружки), измеренные при комнатной температуре. Сплошной и штриховой линиями показаны результаты аппроксимации данных функцией Лоренца.

температурной зависимости радикально меняется, т.е. аномальная динамика матрицы в условиях фазового перехода начинает играть основную роль.

Анализ спектров люминесценции, зависящих от температуры, является косвенным методом получения информации о параметрах локализованных фононов. Для подтверждения полученных данных мы провели дополнительные измерения методом КРС. Низкочастотные спектры КРС в диапазоне от 6 до $230 \mathrm{~cm}^{-1}$ для тонкого слоя КТ на подложке и КТ, внедренных в ПИБ (рис. 2), измеряли при комнатной температуре на спектрометре TriVista 777 с использованием твердотельного лазера Millenia $(532 \mathrm{~nm})$ в ИАЭ СО РАН. Паразитная засветка от лазера подавлялась при помощи монохроматора [25] (подробное описание используемой техники для низкочастотной спектроскопии КРС см., например, в [26]). Для исследуемых образцов в спектре КРС в области $205-206 \mathrm{~cm}^{-1}$ обнаружены полосы, что хорошо соответствует оценкам величины $E_{L O}$ по спектрам люминесценции. Дополнительную информацию о влиянии матрицы на колебательные спектры нанокомпозитов могут дать измерения энергии не только продольных $(L O)$, но и 
поперечных $T O$-фононных мод [27]. Для оболочек из широкозонного полупроводника $\mathrm{CdS}$ и $\mathrm{ZnS}$, органических лигандов и окружающей полимерной матрицы эти компоненты находятся в другом частотном диапазоне. Кроме того, может происходить гибридизация фононных мод [28].

Параметры, полученные из анализа зависящих от температуры спектров люминесценции нанокомпозитов с коллоидными КТ, хорошо согласуются с модельными расчетами и результатами других исследований, что свидетельствует об адекватности выбора модели и достоверности полученных данных.

\section{Заключение}

Для композитов на основе коллоидных КТ $\mathrm{CdSe} / \mathrm{CdS} / \mathrm{ZnS}$ в широком диапазоне низких температур (от 24 до $300 \mathrm{~K}$ ) были измерены температурные зависимости положения спектра люминесценции, связанного c энергией экситона и шириной запрещенной зоны. В рамках модели электрон-фононного взаимодействия определены значения энергии локализованных фононов и фактора Хуанга-Риса. Указанные параметры найдены для трех систем: КТ, высаженные на поверхность стекла методом шаберного нанесения, тонкая полимерная (ПИБ) пленка с внедренными КТ, тонкий (толщиной около $1 \mathrm{~mm}$ ) слой замороженного (застеклованного) коллоидного раствора КТ в толуоле. Заметное отличие параметров найдено для КТ в замороженном толуоле, что может свидетельствовать об эффекте гибридизации мод. В этом же образце выявлено аномальное температурное поведение вблизи температуры стеклования образца. Результаты, полученные методами люминесцентной спектроскопии, хорошо коррелируют с данными по низкочастотному КРС в тех же материалах. Развитый подход позволяет изучать влияние матрицы на спектральные и фотофизические свойства нанокомпозитов.

\section{Финансирование работы}

Исследование выполнено в рамках темы государственного задания Московского педагогического государственного университета „Физика наноструктурированных материалов: фундаментальные исследования и приложения в материаловедении, нанотехнологиях и фотонике“ при поддержке Министерства просвещения РФ (номер государственной регистрации: АААА-А20120061890084-9). Развитие экспериментальной техники спектроскопии фотонного эха выполнено в рамках темы государственного задания Института спектроскопии РАН. Развитие экспериментальной техники люминесцентной микроскопии высокого разрешения выполнено в рамках темы государственного задания Физического института им. П.Н. Лебедева РАН.

\section{Конфликт интересов}

Авторы заявляют, что у них нет конфликта интересов.

\section{Список литературы}

[1] А.М. Майорова. Фотоника, 12, 134 (2018). DOI: 10.22184/1993-7296.2018.69.1.134.142

[2] А.С. Мацукович, О.Ю. Наливайко, К.В. Чиж, С.В. Гапоненко. Журн. прикл. спектр., 86 (1), 84 (2019). [A.S. Matsukovich, S.V. Gaponenko, O.Y. Nalivaiko, K.V. Chizh. J. Appl. Spectr., 86(1), 72 (2019). DOI: 10.1007/s10812-019-00783-8].

[3] K.R. Karimullin, A.V. Naumov. J. Lumin., 152, 15 (2014). DOI: 10.1016/j.jlumin.2014.01.069

[4] A. Bobrovsky, V. Shibaev, S. Abramchuk, G. Elyashevitch, P. Samokhvalov, V. Oleinikov, K. Mochalov. Eur. Polymer. J., 82, 93 (2016). DOI: 10.1016/j.eurpolymj.2016.06.017

[5] K.A. Magaryan, M.A. Mikhailov, K.R. Karimullin, M.V. Knyazev, I.Y. Eremchev, A.V. Naumov, I.A. Vasilieva, G.V. Klimusheva. J. Lumin., 169, 799 (2016). DOI: 10.1016/j.jlumin.2015.08.064

[6] М.С. Смирнов, О.В. Овчинников, И.В. Тайдаков, С.А. Амброзевич, А.Г. Витухновский, А.И. Звягин, Г.К. Усков. Опт. и спектр., $125(2), 240$ (2018). DOI: 10.21883/OS.2018.08.46367.65-18 [M.S. Smirnov, O.V. Ovchinnikov, A.I. Zvyagin, G.K. Uskov, I.V. Taidakov, S.A. Ambrozevich, A.G. Vitukhnovskii. Opt. Spectr., $125(2)$, 249 (2018). DOI: $10.1134 / \mathrm{S} 0030400 X 18080210]$.

[7] С.Б. Бричкин, В.Ф. Разумов. Усп. хим., 85 (12), 1297 (2016). DOI: 10.1070/RCR4656 [S.B. Brichkin, V.F. Razumov. Russ. Chem. Rev., 85, 1297 (2016). DOI: 10.1070/RCR4656].

[8] Р.Х. Гайнутдинов, Л.Я. Набиева, А.И. Гарифуллин, А. Ширделхавар, А.А. Мутыгуллина, М.Х. Салахов. Письма в ЖЭТФ, $\mathbf{1 1 4}(4), 221$ (2021). DOI: $10.31857 / \mathrm{S} 1234567821160047$

[9] В.Б. Капустянык, С.И. Семак, С.Б. Бильченко, Ю.И. Элияшевский, Ю.В. Чорний, П.Ю. Демченко. Журн. прикл. спектр., 86 (4), 531 (2019). [V.B. Kapustianyk, S.I. Semak, S.B. Bilchenko, Y.I. Eliyashevskyy, Y.V. Chorniy, P.Y. Demchenko. J. Appl. Spectr., 86 (4), 590 (2019). DOI: $10.1007 / \mathrm{s} 10812-019-00864-8]$.

[10] И.С. Езубченко, А.С. Трифонов, И.С. Осадько, И.Г. Прохорова, О.В. Снигирев, Е.С. Солдатов. Изв. РАН. Cep. физ., 76 (12) 1465 (2012). [I.S. Ezubchenko, A.S. Trifonov, I.S. Osad'ko, I.G. Prokhorova, O.V. Snigirev, E.S. Soldatov. Bull. RAS. Phys., 76 (12), 1310 (2012). DOI: $10.3103 / \mathrm{S} 1062873812120088]$.

[11] И.С. Осадько. Изв. РАН. Сер. физ., 83 (12), 1594 (2019). DOI: $10.1134 / \mathrm{S} 0367676519120184$

[12] А.И. Аржанов, К.Р. Каримуллин, А.В. Наумов. Кр. сообщ. по физ. Физического института им. П.Н. Лебедева PAH, 45 (3), 39 (2018). [A.I. Arzhanov, K.R. Karimullin, A.V. Naumov. Bull. Lebedev Phys. Inst., 45, 91 (2018). DOI: $10.3103 / \mathrm{S} 1068335618030077]$.

[13] К.Р. Каримуллин, А.И. Аржанов, А.В. Наумов. Изв. РАН. Сер. физ., $82(11), 1620$ (2018). DOI: 10.1134/S0367676518080197. [K.R. Karimullin, A.I. Arzhanov, A.V. Naumov. Bull. RAS. Phys., 82 (11), 1478 (2018). DOI: c10.3103/S1062873818080191]. 
[14] K.R. Karimullin, A.I. Arzhanov, I.Yu. Eremchev, B.A. Kulnitskiy, N.V. Surovtsev, A.V. Naumov. Laser Phys., 29 (12), 124009 (2019). DOI: 10.1088/1555-6611/ab4bdb

[15] К.А. Магарян, К.Р. Каримуллин, И.А. Васильева, А.В. Наумов. Опт. и спектр., $126(1), 50$ (2019). DOI: $10.21883 / \mathrm{OS} .2019 .01 .47052 \quad$ [K.A. Magaryan, K.R. Karimullin, I.A. Vasil'eva, A.V. Naumov. Opt. Spectr., 126 (1), 41 (2019). DOI: 10.1134/S0030400X19010107].

[16] А.Г. Милёхин, Л.Л. Свешникова, Т.А. Дуда, Н.В. Суровцев, С.В. Адищев, Д.Р.Т. Цан. Письма в ЖЭТФ, 88 (12), 918 (2008). [A.G. Milekhin, L.L. Sveshnikova, T.A. Duda, N.V. Surovtsev, S.V. Adichtchev, D.R.T. Zahn. JETP Lett., 88 (12), 799 (2008). DOI: 10.1134/S0021364008240053].

[17] K.R. Karimullin, M.V. Knyazev, A.I. Arzhanov, L.A. Nurtdinova, A.V. Naumov. J. Phys. Conf. Ser., 859, 012010 (2017). DOI: 10.1088/1742-6596/859/1/012010

[18] К.Р. Каримуллин, А.И. Аржанов, А.В. Наумов. Изв. РАН. Сер. физ., $\mathbf{8 1}(12), 1581$ (2017). DOI: $10.7868 / \mathrm{S} 0367676517120043$ [K.R. Karimullin, A.I. Arzhanov, A.V. Naumov. Bull. RAS. Phys., 81 (12), 1396 (2017). DOI: 10.3103/S1062873817120164].

[19] Y.P. Varshni. Physica, 34 (1), 149 (1967). DOI: 10.1016/00318914(67)90062-6

[20] И.А. Вайнштейн, А.Ф. Зацепин, В.С. Кортов. ФТТ, 41 (6), 994 (1999). [I.A. Vǎ̌nshteřn, A.F. Zatsepin, V.S. Kortov. Phys. Solid State, 41 (6), 905 (1999). DOI: 10.1134/1.1130901].

[21] K.P. O'Donnell, X. Chen. Appl. Phys. Lett., 58 (25), 2924 (1991). DOI: 10.1063/1.104723

[22] A. Al Salman, A. Tortschanoff, M.B. Mohamed, D. Tonti, F. van Mourik, M. Chergui. Appl. Phys. Lett., 90, 093104 (2007). DOI: 10.1063/1.2696687

[23] А.Е. Еськова, А.И. Аржанов, К.А. Магарян, К.Р. Каримуллин, А.В. Наумов. Изв. РАН. Сер. физ., 84 (1), 48 (2020). DOI: 10.31857/S036767652001012 [A.E. Eskova, A.I. Arzhanov, K.A. Magaryan, K.R. Karimullin, A.V. Naumov. Bull. RAS. Phys., 84 (1), 40 (2020). DOI: 10.3103/S1062873820010116].

[24] S. Baskoutas, A.F. Terzis. J. Appl. Phys., 99(1), 013708 (2006). DOI: $10.1063 / 1.2158502$

[25] N.V. Surovtsev. Optoelectron. Instrum. Data Process., 53, 250 (2017). DOI: 10.3103/S8756699017030086

[26] D.V. Leonov, S.V. Adichtchev, S.A. Dzuba, N.V. Surovtsev. Phys. Rev. E, 99, 022417 (2019). DOI: 10.1103/PhysRevE.99.022417

[27] R.M. Abozaid, Z.Z. Lazarevic, I. Radaviv, M. Gilic, D. Sevic, M.S. Rabasovic, V. Radojevic. Opt. Mater., 92, 405 (2019). DOI: 10.1016/j.optmat.2019.05.012

[28] A.J. Mork, E.M.Y. Lee, N.S. Dahod, A.P. Willard, W.A. Tisdale. J. Phys. Chem. Lett., 7, 4213 (2016).

DOI: 10.1021/acs.jpclett.6b01659 